\title{
Territorios de la furia ${ }^{1}$
}

Rodrigo Ganter Profesor, Instituto de Estudios Urbanos y Territoriales, Pontificia Universidad Católica de Chile y Departamento de Sociología y Antropología, Universidad de Concepción.

Probablemente como resultado de la superposición de procesos de segregación, conflic tos políticos y una cultura disciplinada, La Legua se ha consolidado como una entidad reconocible dentro del tejido urbano de Santiago. Más que su realidad espacial, han sido la estructura de su comunidad y su cultura las que han marcado con precisión sus límites.
La Legua has likely consolidated as a recognizable entity within the urban weave of Santiago because of the superposition of segregation, political conflicts and a disciplined culture. The structure of its community and its culture have been what have marked its boundaries with precision, rather than its spatial reality.

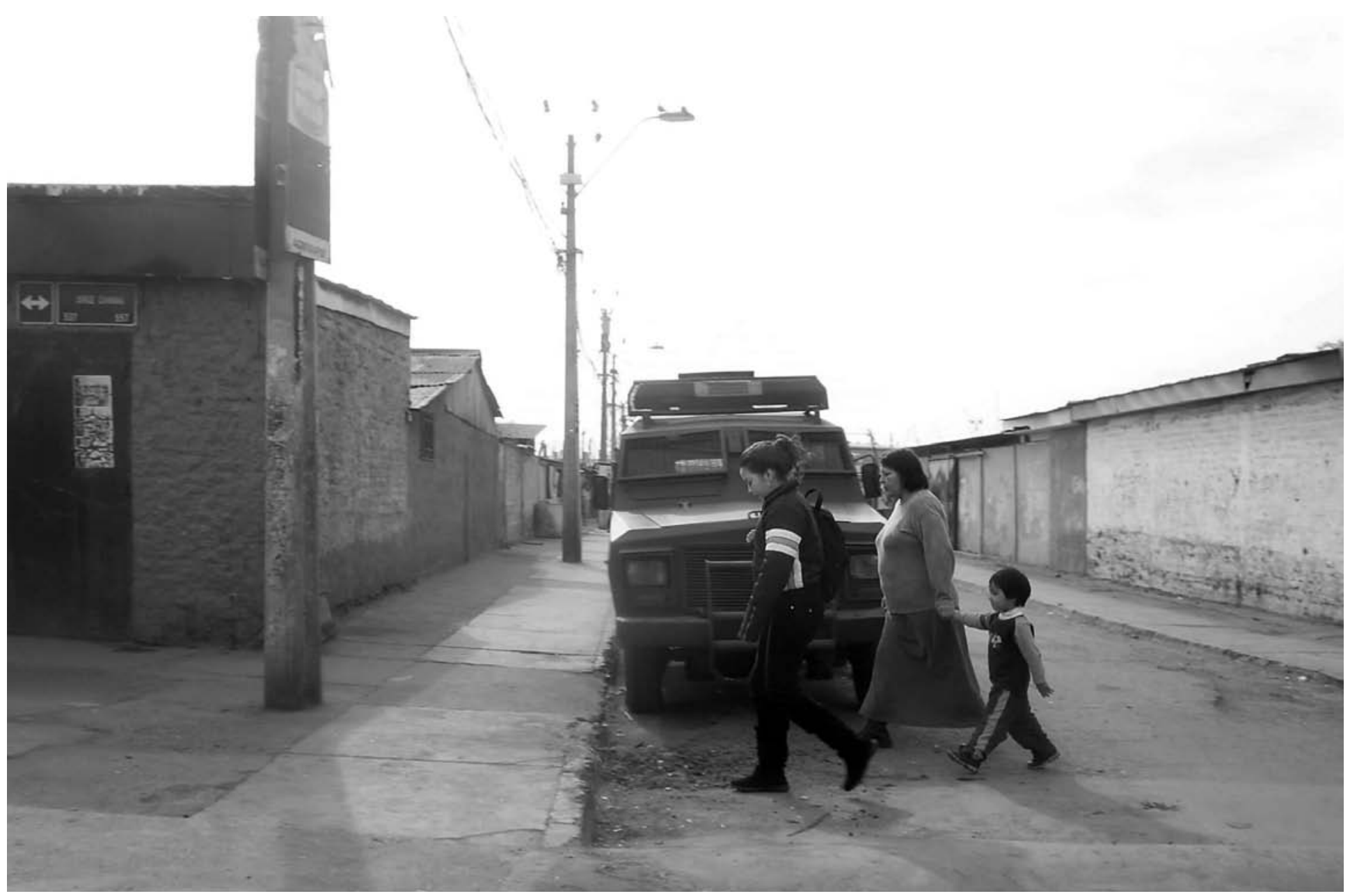

01 Población Legua Emergencia. Fotografía del autor

UnA CONTRA-LECTURA DE LA POBLACión La Legua / Antes de ingresar en el texto resulta fundamental develar el territorio existencial (Guattari, 1998) desde donde se escribe. Dicho territorio da cuenta de una posición fronteriza entre las figuras del afuerino y del oriundo, pues el presente artículo no se escribe ni como un habitante o residente típico del lugar al cual el texto convoca (observador de primer orden: sedentario), ni tampoco como un completo extranjero (observador de segundo orden: nómade). Tras compartir experiencias con algunos de los colectivos que componen la comunidad legüina es posible desarrollar un texto de composición híbrida y compleja, que pretende dar cuenta -siempre precariamentede una actualidad cargada de memorias sociales que se disputan permanentemente la construcción de dicho territorio.
CONFIGURANDO GENEALOGÍAS TERRITORIALES ${ }^{2}$ / La Legua es una población ${ }^{3}$ emblemática de la zona suroriente de Santiago que se asentó inicialmente en la tradicional comuna de San Miguel. Después de la reforma comunal de 1981, el territorio de La Legua quedó en la actual comuna de San Joaquín, y desde entonces hasta ahora a una sola legua de distancia de la Plaza de Armas, de ahí deriva su nombre .

La Legua se configuró a partir de tres fases de asentamiento iniciadas en la primera parte del s. XX. Existe consenso, tanto en la opinión de historiadores como en las diversas fuentes consultadas, que la primera fase de poblamiento se inició a partir de 1931.

Esta primera etapa, que podríamos llamar fundacional, estaría definida por el arribo de un contingente de obreros cesantes proceden- 
${ }^{1}$ El presente texto constituye un fragmento de la investigación etnográfica que el autor se encuentra actualmente realizando en el contexto de la población La Legua Emergencia en Santiago de Chile, y que forma parte de su proyecto de tesis doctoral Identidades urbanas y estigmatización territorial: cartografias de La Legua Emergencia. bibliografía, se han timonios prove pobladores de La Legua.

${ }^{3}$ Entenderemos aquí por población a un asentamiento humano preferentemente urbano, denso y popular, que según A de Ramón (1985) constituye la tipología más an el mapa urbano, luego se sumarían en menor escala las poblaciones sectos, con expansión perif Santiago a partir de 1860

${ }^{4}$ Legua: medida itineraria que equivale a cinco kilómetros y medio aprox. (5.572.7 metros) lo que se trax. (5.572,7 metros), lo que se

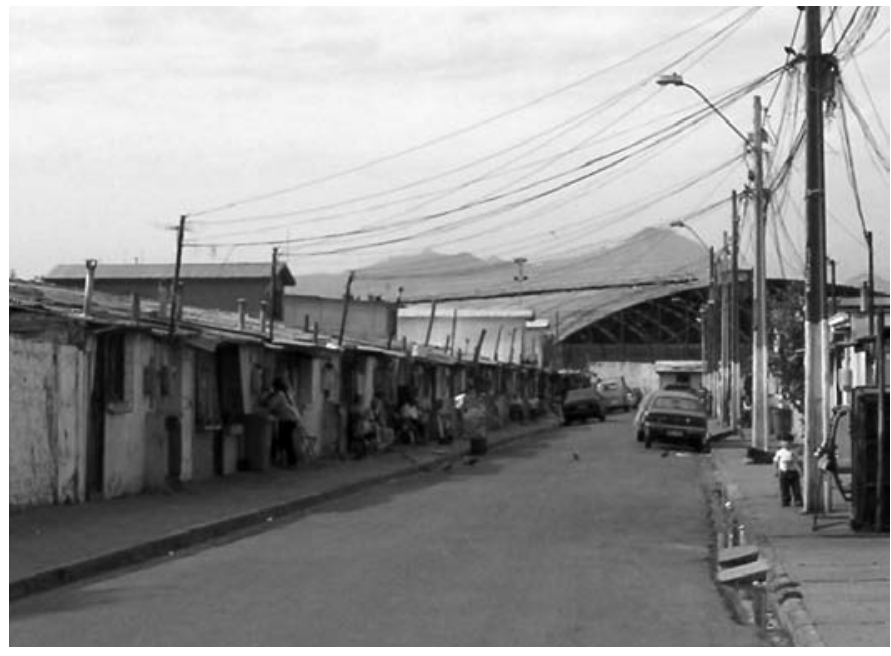

02 Población Legua Emergencia. Fotografía de Alexis, fundador colectivo Furia Legüina

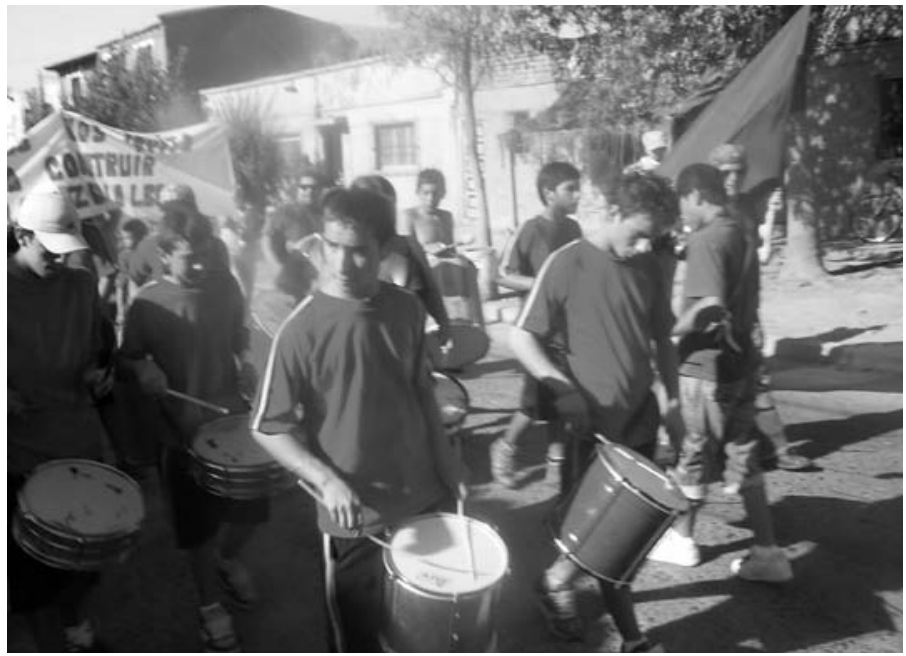

03 Colectivo Furia Legüina en marcha por la paz. Fotografía de Alexis tes de las salitreras del norte de Chile, en un momento histórico de declinación de esa industria.

Respecto de su planta urbana fundacional, es posible señalar que existen signos, como la conectividad de alguna de sus calles y la distribución paralela de las mismas, que estarían indicando la posibilidad que haya sido planificada antes de su poblamiento (Jakel, 2004). Con el devenir de los años, dicho territorio recibiría el nombre de Villa Santa Rosa, conocida popularmente como población Legua Vieja y que en rigor constituiría, en su acepción moderna, la población más antigua de Chile (Garcés, 1999) y cuya identidad de origen sería básicamente obrera.

La segunda fase de poblamiento se conoce como población Nueva La Legua. En esta fase se pueden encontrar al menos tres momentos históricos definidos por el arribo al territorio de diversas identidades urbanas. Un primer momento está definido por la llegada en 1947 de un grupo aproximado de 38 familias, en su mayoría procedente de las riberas del Zanjón de la Aguada. Este grupo se instaló entre la avenida Santa Rosa y la calle Sierra Bella.

Un segundo momento está definido por la llegada de un grupo de colonos procedente de la famosa toma del barrio Zañartu de Ñuñoa (1947), próxima a la actual ubicación del Estadio Nacional, y que es considerada como la primera toma organizada de sitios en Santiago (ECO/FOSIS, 1999). Este contingente de pobladores estaba conformado por 700 familias. Su capital organizacional les permitió hacerse escuchar por la autoridad y lograr que se los trasladara en 1948 a un lugar definitivo, llegando así a la población La Legua.

Un tercer momento está definido por la incorporación de diversas familias procedentes de la población El Peral, la población Rosamarma y la población Sudamérica, sumando un total aproximado de 450 familias. Finalmente, en el año 1951, se inicia la tercera fase de poblamiento. En esos momentos la Municipalidad de San Miguel aprobó un loteo de sitios para que la Caja de Habitación ${ }^{5}$ instalara de modo provisorio a un nuevo grupo de familias en el sector de la población La Legua, asignándoles viviendas de emergencia cuando el problema habitacional hacía crisis en Santiago. No obstante, este asentamiento se transformó en definitivo y hasta la fecha se le identifica como población Legua Emergencia.

A este territorio llegó un grupo de identidades urbanas compuesto preferentemente por dos estratos de familias: un primer grupo de aproxi- madamente 200 familias provenía de la Manzana del Alto, un antiguo barrio obrero configurado por conventillos fuertemente degradados y que estaban ubicados entre el parque Quinta Normal y la estación Yungay. Esta operación de traslado a la actual población Legua Emergencia fue organizada por la Caja de Habitación. El segundo contingente de familias provendría de poblaciones callampas ${ }^{6}$ ubicadas en la ribera norte del río Mapocho y en el canal La Punta, en el sector de Independencia. Quedó, de este modo, organizada la Legua Emergencia en dos subsectores. El sector I, comprendido entre los pasajes Santa Elisa (poniente) y Sánchez Colchero (oriente) y el sector II, comprendido entre los pasajes Venecia (poniente) y San Gregorio (oriente) ${ }^{7}$.

Una de las particularidades de la población La Legua Emergencia, y que se mantiene en gran medida desde sus orígenes hasta nuestros días, se asocia con su carácter de territorio encajonado. Esto debido a que el perímetro que la circunda se encuentra fuertemente delimitado y jerarquizado.

Ahora bien, en la historia más reciente, La Legua destaca -en el imaginario colectivo- por ser una población de izquierda y por la resistencia demostrada frente al golpe de Estado del 11 de septiembre de 1973. Más aún destaca por haber sido la única comunidad urbana que se desplegó ofensivamente frente a las fuerzas militares y de Carabineros que dicho día incursionaron en su territorio.

La identidad de La Legua también ha sido asociada con la experiencia de ser una de las poblaciones más fuertemente reprimidas por el régimen militar durante los setenta y los ochenta. Y al mismo tiempo por ser un enclave con una vasta y potente red de organizaciones sociales, culturales, económicas, de derechos humanos, políticas y religiosas ${ }^{8}$ que, en definitiva, le permitieron a su comunidad crear estrategias para sobrevivir al hambre, la represión, el aislamiento, la cesantía y la opresión.

Pero la historia oral y testimonial también apunta a identificar a la comunidad legüina con la contra-cultura urbana inscrita en el campo del delito. La Legua ha sido tradicionalmente una población de choros ${ }^{9}$, y no sólo de choros que desarrollan su oficio en los circuitos locales, sino que también en una escala internacional y global. Esta contra-cultura urbana que además se expresa -histórica y contingentemente- como un fenómeno más capilar y estratificado, en el caso de La Legua Emergencia se configura en una práctica profundamente imbricada en el tejido comunitario de la población. 
${ }_{5}^{5}$ Creada por el gobierno en el año 1936 con el objetivo de generar una institucionalidad en materia de vivienda, siendo el antecedente directo de la CORVI creada posteriormente en el año 1953. El objetivo de corto plazo de la Caja de Habitación estaba definido por el saneamiento de conventillos $y$ barios obreros degradados, dirigendo el esfuerzo de su política habitacional hacia la clase trabajadora y los empleados públicos, como Carabineros. Sobre esta materia resulta relevante consignar que a partir del año 1945 el problema habitacional comienza a declara como de emerenia, derivándose a su vez estrategias de emergen para enfrentar los problemas habitacionales más críticos.
6 Para el caso de Chile recibe esta denominación el grupo de casas pobres que surgen súbitamente y se expanden como si fueran callampas u hongos, generalmente ubicadas a la orilla de un río o canal.

7 Cabe resaltar que la construcción de la población La Legua Emergencia fue diseñada a través de pasajes que se desprendían de que se desprendían de una calle principal. Estos fueron construidos para disponer hileras de alrededor de treinta casas continuas, pareadas y que mantenían una misma líne de fachada. Según los actuales informes del DIDECO de la llustre Municipalidad de San Joaquí, La Legua Emergencia posee una superficie aprox. de 15,36 ha, con un total aprox. de 1.093 viviendas de $3 \times 22 \mathrm{~m}$, inscritas en una trama urbana cuya morfología es análoga a la espina dorsal de un pez

Sobre el protagonismo de la Iglesia Católica en el territorio de La Legua aparecen las destacadas figuras de los padres Rafael Maroto y Mariano Puga. por lo general de estratos populares y que han estado muchas veces en prisión, razón por la cual conocen y manejan los códigos del hampa.

10 Conformando el $14,3 \%$ de la población total de la comuna de San Joaquin tes es de 97.562 según las cifras del Censo de población 2002. Sobre este punto profundizar los datos censales en: "Diagnóstico Comunitario para la Población La Legua Emergencia" (2006) elaborado por la Dirección de (2006), elaborado por la Dirección de pasar de Seguridad Ciudadana del Ministerio del Interior de Chile.

1 Ello como parte de la Intervención Policial aplicada a partir de añ 2001 en La Legua Emergencia ano 2001 en La Legua Emergencia en el contexto del programa Barrio Seguro de la División de Seguridad del Ministerio del Interior.

12 La batucada tiene sus raíces en las culturas africanas primigenias donde la percusión ligada a las fordacion maciones de tambores constituyen el elemento básico para las fes dades religiosas y populares.
En la actualidad las tres Leguas, que en realidad forman una sola y sofisticada trama socio-territorial poblada por una diversidad compleja de subjetividades colectivas, tiene una población total de 14.011 habitantes ${ }^{10}$, desagregada del siguiente modo: 2.878 habitantes en La Legua Vieja, 6.218 habitantes en la Nueva La Legua, 4.915 habitantes en La Legua Emergencia.

En estos días, La Legua y muy particularmente La Legua Emergencia están siendo afectadas por profundos problemas sociales y muy especialmente por el deterioro de las redes asociativas, tanto de sobrevivencia como de acción política, dibujándose como una comunidad fragmentada, debilitada en sus capacidades para producir nuevas sociabilidades.

LA OTRA FURIA URBANA / Dada la problemática descrita anteriormente, el supuesto básico con el que partimos es que, en cierto modo, nos encontramos en presencia de un territorio donde funciona un espacio público que difícilmente se puede asociar con aquel lugar ideal de encuentro e intercambio social multi-identitario, operando más bien como un espacio de conflicto urbano entre fuerzas sociales de diverso linaje; un espacio en disputa por la hegemonía cultural, urbana y, en cierto modo, militar, donde es posible observar en los últimos años un cierto proceso de privatización y/o expropiación del espacio público en la población La Legua Emergencia, tanto por fuerzas del Estado, en este caso Carabine$\operatorname{ros}^{11}$, como por fuerzas ligadas al narcotráfico, quedando los pobladores en una encrucijada entre el temor, la resistencia a la trama de poderes que intenta domesticarlos y las incipientes prácticas de re-apropiación creativa de dicho espacio.

En este último sentido, es posible observar en la actualidad incipientes pero significativas señales de cambio en La Emergencia. Esto último a partir de la aparición de nuevos protagonismos sociales y culturales inscritos en dicho territorio. Uno de estos casos es el del colectivo Furia Legüina, agrupación de jóvenes que practican la batucada $a^{12}$ y con ello la re-apropiación de la calle, de los espacios públicos y comunitarios de La Legua.

La red de Organizaciones Sociales de La Legua Emergencia, la red OLE, está compuesta por una diversidad de organizaciones que operan en su territorio. Genealógicamente, esta red se encuentra emparentada con la agrupación Amigos por la Paz, una organización anterior a la articulación de la red y que se habría formado con el objetivo de disputarle el espacio público tanto al miedo generado por las balas de las bandas de narcos, como a la propia presencia de las fuerzas policiales de Carabineros en el territorio de La Emergencia.

Según nos cuenta Alexis, uno de los jóvenes fundadores de Furia Legüina, el año 2006 sería el segundo año en que se realiza el Carnaval de los 500 Tambores por la Paz y la Vida en la población La Legua, donde participan cerca de 500 artistas mostrando sus diversas disciplinas en un territorio que durante un día se vuelca hacia las calles de la población. Así los pobladores comienzan a promover y desarrollar, a través de estos formatos culturales, el principio y la práctica de la no violencia activa, con el objetivo de recuperar y rehabilitar, desde abajo y desde adentro, su propio territorio.

Finalmente, pese al estigma cultural construido por los discursos sociales e institucionales hegemónicos sobre La Legua, los pobladores y las pobladoras en su mayoría constituyen biografías entretejidas por grandes luchas y sacrificios. Ellos posibilitaron la consolidación y la habilitación estructural y comunitaria de dicho asentamiento humano, generando no sólo la incorporación de los servicios básicos y la infraestructura necesaria, sino también -y por sobre todo- produciendo una trama de afectos e inteligencias colectivas que, en su tiempo y hasta ahora, se rearticulan en un imaginario y un proyecto de ciudad que lucha contra la exclusión social y las diferentes formas de violencia impuestas cotidianamente sobre su territorio. ARQ

\section{Bibliografía}

De Ramón, Armando. Estudio de una periferia urbana: Santiago de Chile 18501900. Instituto de Historia, Pontificia Universidad Católica de Chile, Santiago, 1985. / Dirección de Desarrollo Comunitario de la Municipalidad de San Joaquín y División de Seguridad Ciudadana del Ministerio del Interior de Chile. Diagnóstico Comunitario para la población La Legua Emergencia, Documento de trabajo, Santiago, 2006. / ECO, Educación y Comunicaciones y Monitores de La Legua. Propuesta Comunitaria de prevención para La Legua, Documento de trabajo, Santiago, 2003. / Garcés, Mario. El Golpe en la Legua. LOM Ediciones, Santiago, 2005. / Guattari, Félix. El Devenir de la Subjetividad. Ediciones Dolmen, Santiago, 1998. / Jakel, Timo. Los espacios habitados de Legua Emergencia. Documento de apoyo "Proyecto Legua", Universidad Diego Portales, Santiago, 2004. / Red de Organizaciones Sociales de La Legua y ECO, Educación y Comunicaciones. Lo que se teje en La Legua: historia, poesía y canciones de su gente. Editado por ECO/FOSIS, Santiago, 1999. 